E3S Web of Conferences 1, 17004 (2013)

DOI: $10.1051 / \mathrm{e} 3$ sconf/20130117004

(c) Owned by the authors, published by EDP Sciences, 2013

\title{
Speciated mercury measurements in ambient air from 2009 to 2011 at a Central European rural background monitoring site
}

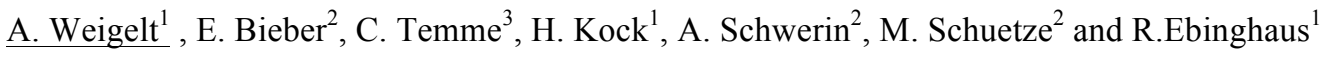 \\ ${ }^{1}$ Helmholtz-Zentrum Geesthacht, Institute of Coastal Research, Max-Planck-Str. 1, D-21502 Geesthacht, Germany, \\ Andreas.Weigelt@hzg.de; Hans.Kock@hzg.de; Ralf.Ebinghaus@hzg.de \\ ${ }^{2}$ Federal Environment Agency, Air Pollution Monitoring Network, Paul-Ehrlich-Str. 29, D-63225 Langen, Germany, \\ elke.bieber@uba.de \\ ${ }^{3}$ Eurofins GfA GmbH, Neulaender Kamp 1, D-21079 Hamburg, Germany, ChristianTemme@eurofins.de
}

\begin{abstract}
Since January 2009 highly time-resolved mercury speciation measurements in ambient air are carried out at the Central European German EMEP monitoring station and measurement site of the German Federal Environment Agency "Waldhof", providing the longest Central European dataset for mercury species. First statistical analyses do not indicate long term trends for the concentrations of gaseous elemental mercury (GEM) and particle bound mercury (TPM). A potential increasing trend for reactive gaseous mercury (RGM) will have to be verified in the coming years and should be regarded as indicative only at present. A seasonal cycle for TPM could be observed with higher concentrations during winter time. Furthermore a diurnal cycle for RGM is apparent with highest concentrations in the early afternoon.
\end{abstract}

Key words: atmospheric mercury speciation measurements, trend measurements, seasonality in mercury species, GMOS

\section{Introduction}

Mercury $(\mathrm{Hg})$ is a very toxic and therefore perilous substance for human health and the environment. Following the food chain, it is accumulated in organisms mainly as methylmercury. Once emitted, mercury distributes most effective in the atmosphere. The most important anthropogenic sources for the atmospheric mercury are fossil fuel combustion, smelting, cement production, and waste incineration (Pirrone et al., 2009; Pacyna et al., 2006; 2010) The largest natural sources for atmospheric $\mathrm{Hg}$ are oceans (Pirrone et al., 2009; Ferrara et al., 2000; Mason 2009).

Atmospheric mercury can be divided into gaseous elemental mercury (GEM or $\mathrm{Hg}^{0}$ ), reactive gaseous mercury (RGM or $\mathrm{Hg}^{2+}$ ), and particle bound mercury (TPM or $\mathrm{Hg}^{\mathrm{p}}$ ) (Lindberg et al., 1998). The latter fractions are operationally defined. GEM and RGM are summarized to total gaseous mercury (TGM). Because RGM and TPM are highly water soluble, they are easily removed from the atmosphere, e.g. by wet scavenging. Compared to GEM their atmospheric life time is very short (days vs. several months up to $1 \mathrm{y}$; Schroeder and Munthe, 1998). Atmospheric concentrations of RGM and
TPM are found to be typically much lower than of GEM (1 to $5 \%$ of GEM; Schroeder and Munthe, 1998). Within this work we will present data from a Central European rural background site performing long term speciated mercury measurements.

\section{Materials and Methods}

Measurement Location

Since January 2009 the atmospheric concentrations of GEM, RGM, and TPM are measured continuously at the German EMEP monitoring station and measurement site of the German Federal Environment Agency "Waldhof" (hereafter called Waldhof). This site is located in a Central European flat terain $\left(52^{\circ} 48^{\prime} \mathrm{N}, 10^{\circ} 45^{\prime} \mathrm{E}\right)$, about $100 \mathrm{~km}$ south-east of Hamburg, Germany. Waldhof is well established as Central European atmospheric rural background monitoring site. When the Global Mercury Observation System project (GMOS; www.gmos.eu) started in November 2010, Waldhof was chosen to be one of four European GMOS master sites, measuring continuously fully speciated mercury concentrations.

The measurements are performed in quasi- 


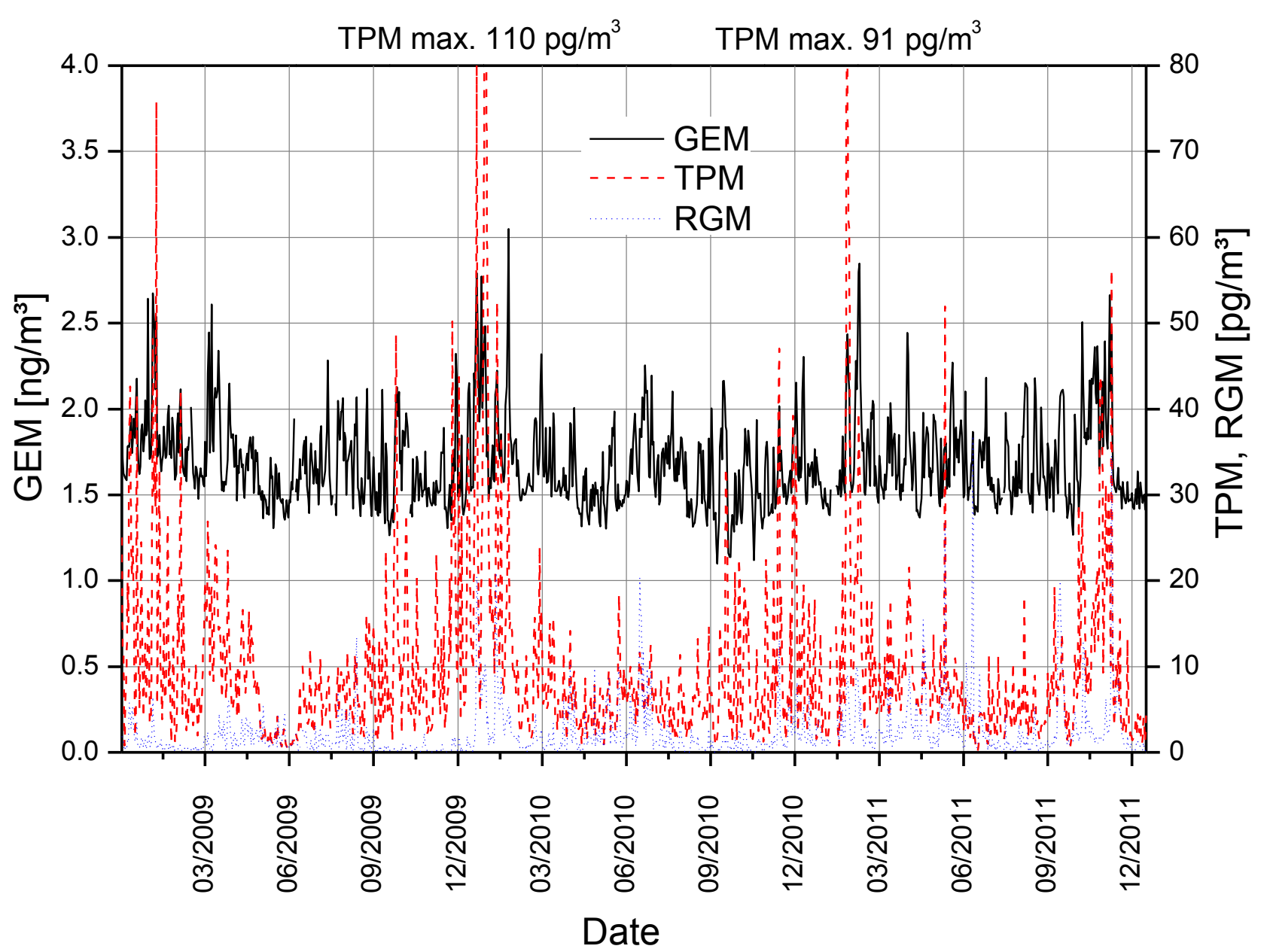

Fig. 1. Daily averages for gaseous elemental mercury (GEM), particle bound mercury (TPM), and reactive gaseous mercury (RGM) from January 2009 to December 2011 at the German EMEP station and measurement site of the German Federal Environment Agency "Waldhof".

continuous mode, using an automatic mercury analyzer (Tekran model 2537A) together with a mercury speciation unit (Tekran model 1130 and Tekran model 1135). The measurement principle of the automatic mercury analyzer is based on cold vapor atomic flourescence spectroscopy (CVAFS). While the Tekran 2537A measures GEM with a temporal resolution of five minutes, RGM and TPM are trapped from the measurement air on a $\mathrm{KCl}$ coated denuder (Tekran unit 1130; RGM) and a particle filter (Tekran unit 1135; TPM), respectively. After three hours of sampling, the trapped RGM and TPM is thermally desorbed, transformed to GEM and becomes detected with the Tekran 2537A. While RGM and the TPM are desorbed, sampling is interrupted for 85 minutes. Detailed information on the Tekran mercury speciation unit can be found under www.tekran.com.

\section{Results and Discussion}

Figure 1 illustrates the daily average concentrations for GEM (black), TPM (red), and RGM (blue), measured from January 2009 until December 2011. During this three year period the daily median GEM concentrations vary between $1.4 \mathrm{ng} / \mathrm{m}^{3}$ and $2.0 \mathrm{ng} / \mathrm{m}^{3}(10 \%$ and $90 \%$ percentile). The minimum and maximum daily average concentrations are found to be $1.1 \mathrm{ng} / \mathrm{m}^{3}$ and $3.1 \mathrm{ng} / \mathrm{m}^{3}$, respectively. The three year median concentration is calculated to be $1.63 \mathrm{ng} / \mathrm{m}^{3}$, which is in agreement to the northern hemispheric background concentration of $1.7 \mathrm{ng} / \mathrm{m}^{3}$ (Ebinghaus et al., 2011). With $6.74 \mathrm{pg} / \mathrm{m}^{3}$ the median TPM concentration is found to be about five times higher than the median RGM concentration of $1.27 \mathrm{pg} / \mathrm{m}^{3}$. TPM and RGM show a much stronger variability in daily average concentrations than GEM. For TPM the $10 \%$ and $90 \%$ percentiles are found to be $2.12 \mathrm{pg} / \mathrm{m}^{3}$ and $19.88 \mathrm{pg} / \mathrm{m}^{3}$, respectively (min. < $0.4 \mathrm{pg} / \mathrm{m}^{3}$ (lower detection limit), max. $110 \mathrm{pg} / \mathrm{m}^{3}$ ). 10\% and $90 \%$ percentiles for RGM are $<0.4 \mathrm{pg} / \mathrm{m}^{3}$ (calculated $0.21 \mathrm{pg} / \mathrm{m}^{3}$ ) and $5.18 \mathrm{pg} / \mathrm{m}^{3}$, respectively (min. < $0.4 \mathrm{pg} / \mathrm{m}^{3}$, max. $37 \mathrm{pg} / \mathrm{m}^{3}$ ). As the arithmetic mean is more sensitive to extreme values, the median value is used for all above presented average concentrations.

Based on yearly median concentrations, between 2009 and 2011 there is no trend apparent for GEM and TPM (Tab. 1). 
Table 1. Yearly average concentrations (medians) for REM, TPM, and RGM, measured at German EMEP station and measurement site of the German Federal Environmental Agency "Waldhof".

\begin{tabular}{|c|c|c|c|}
\hline Year & $\begin{array}{c}\text { GEM } \\
\left(\mathrm{ng} / \mathrm{m}^{3}\right)\end{array}$ & $\begin{array}{c}\text { TPM } \\
\left(\mathrm{pg} / \mathrm{m}^{3}\right)\end{array}$ & $\begin{array}{c}\mathrm{RGM} \\
\left(\mathrm{pg} / \mathrm{m}^{3}\right)\end{array}$ \\
\hline 2009 & 1.66 & 7.20 & 0.73 \\
\hline 2010 & 1.61 & 6.68 & 1.29 \\
\hline 2011 & 1.61 & 6.42 & 1.72 \\
\hline
\end{tabular}

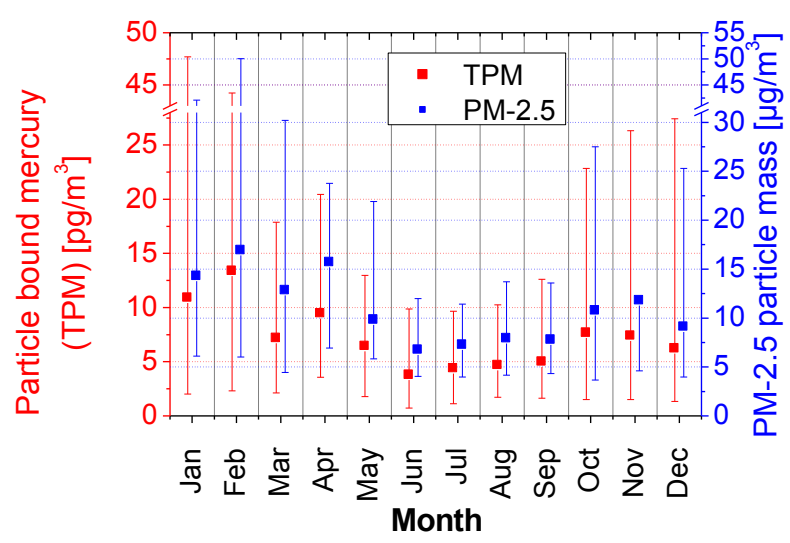

Fig. 2. Monthly median concentrations for particle bound mercury (red) and PM2.5 mass (blue) at the Waldhof site (2009 to 2011). Squares represent the median concentration and error bars indicate the $10 \%$ and $90 \%$ percentile. Please note the braked Y-axis for both parameters. The November PM2.5 90\% percentile is within the braked at $32 \mu \mathrm{g} / \mathrm{m}^{3}$.

Contrary, the yearly median RGM concentration increases by $76 \%$ from 2009 to 2010 and by $34 \%$ from 2010 to 2011. However, due to statistical limitations of the data set ( 3 years of measurements, 1 site), the indicated trend has to be verified by continuing the measurements in the coming years. Nevertheless the indicated trend might point to an increased atmospheric oxidation rate for mercury.

Using the three years dataset, a first seasonality analysis can be carried out by calculating monthly average concentrations. The most pronounced seasonal variation is found for TPM (Fig. 2). While the squares in Fig. 2 represent the median concentrations, the error bars indicate the $10 \%$ and $90 \%$ percentiles. It is apparent, during winter time the concentration, as well as the variability are much higher than in summer. Beside TPM, the PM2.5 mass concentration of suspended particulate matter (fraction of suspended particulate matter which passes through a size-selective inlet with a $50 \%$ cut-off efficiency at $2.5 \mu \mathrm{m}$ aerodynamic diameter) is given in Fig. 2 in blue. The PM2.5 data are averaged for the same time periods as the TPM data. It is obvious, that TPM concentrations show a similar seasonality as the PM2.5 mass concentrations. Higher PM2.5 mass concentrations in winter reflect increased emissions in winter time (e. g. from domestic heating) as well as meteorological effects (e.g. reduced height of the planetary boundary layer;

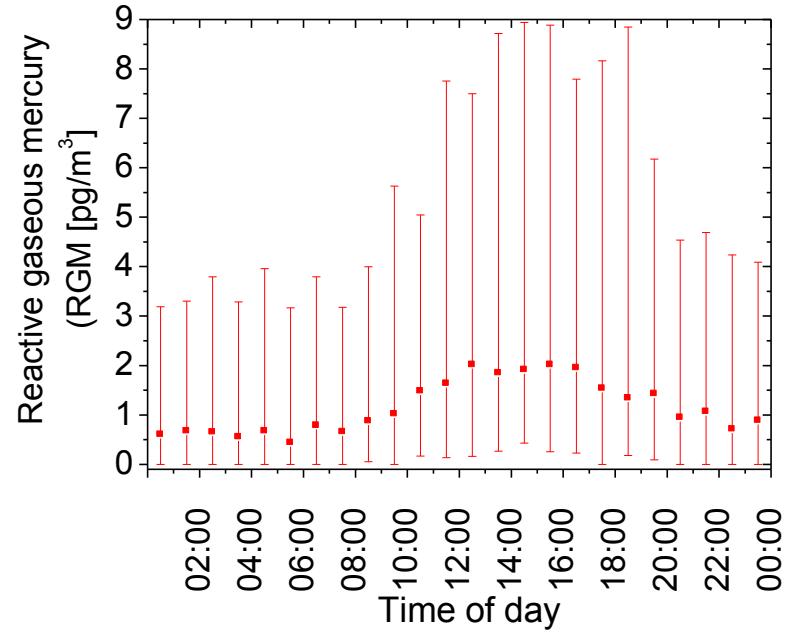

Fig. 3. Hourly median concentrations for reactive gaseous mercury. Data are binned to one hour intervals and averaged between 2009 and 2011. Squares represent the median concentration and error bars indicate the $10 \%$ and $90 \%$ percentile.

(Seinfeld and Pandis, 1998; p. 766-775)).

TPM and RGM are measured with a temporal resolution of 4 hours 25 minutes ( $3 \mathrm{~h}$ sampling, $1 \mathrm{~h}$ analysis, and $25 \mathrm{~min}$. function check). For the statistical analysis all data are binned to one hour intervals. Within three years for each interval at least 195 measurements (TPM, RGM) are carried out. Neither GEM, nor TPM show a significant diurnal cycle (not shown here). On the contrary, for RGM a daily cycle becomes apparent (Fig. 3). At night time the concentration stays relatively constant. From 08:00 local time the concentration increases, reaching maximum values in the early afternoon. At about 16:00 local time RGM concentration decreases until midnight. Currently it is assumed that the observed cycle is caused by local photochemical oxidation and in situ production of RGM.

\section{Acknowledgements}

This work is financially supported by the European Union (Project ENV.2010.4.1.3-2 Global Observing Systems for Mercury) and by the German Federal Environment Agency (Project 35101060 „Determination of mercury species (TGM, GEM, RGM, TPM) in ambient air)".

\section{Conclusion}

Within this work the longest continuous Central European time series for fully speciated mercury measurements is presented. The median GEM concentration $\left(1.63 \mathrm{ng} / \mathrm{m}^{3}\right)$ is found to be typical for northern hemispheric rural background. With $6.74 \mathrm{pg} / \mathrm{m}^{3}$, the median TPM concentration is about five times higher than the median RGM concentration $\left(1.27 \mathrm{pg} / \mathrm{m}^{3}\right)$. First trend analyses do not reveal trends from 2009 to 2011 for 
GEM and TPM, but an increasing concentration for RGM is indicated. However, due to the limited time period the indicated trend has to be verified by future measurements. The observed seasonality for TPM correlates with the PM2.5 particle mass concentration. Higher concentrations are found in winter time and lower concentrations during summer. Diurnal cycle analysis indicate a cycle for RGM, but not for GEM and TPM.

\section{References}

Ebinghaus, R., S.G. Jennings, H.H. Kock, R.G. Derwent, A.J. Manning, T.G. Spain, 2011, Decreasing trends in total gaseous mercury in baseline air at Mace Head, Ireland from 1996 to 2009, Atmospheric Environment, 45, 3475-3480.

Ferrara, R., et al., 2000. Volcanoes as emission sources of atmospheric mercury in the Mediterranean basin. Water Air and Soil Pollution 259, 7.

Lindberg, S.E., W.J. Stratton, 1998, Atmospheric Mercury Speciation: Concentrations and behaviour of reactive gaseous mercury in ambient air, Environmental Science and Technology, 32, 49-57.

Mason, R.P., 2009. Mercury emissions from natural processes and their importance in the global mercury cycle. In: Pirrone, N., Mason, R.P. (Eds.), Mercury Fate and Transport in the Global
Atmosphere. Springer, Dordrecht.

Pacyna, E.G., Pacyna, J.M., Sundseth, K., Munthe, J., Kindborn, K., Wilson, S., Steenhuisen, F., Maxson, P., 2010. Global emission of mercury to the atmosphere from anthropogenic sources in 2005 and projections to 2020. Atmospheric Environment 44, 2487-2499.

Pacyna, E., Pacyna, J.M., Steenhuisen, F., Wilson, S., 2006. Global anthropogenic mercury emission inventory for 2000. Atmospheric Environment 40, 4048-4063.

Pirrone, N., et al., 2009. Global mercury emissions to the atmosphere from natural and anthropogenic sources. In: Pirrone, N., Mason, R.P. (Eds.), Mercury Fate and Transport in the Global Atmosphere: Emissions, Measurements, and Models. Springer, pp. 3-49.

Pirrone, N., Keeler, G.J., Nriagu, J.O., 1996. Regional differences in worldwide emissions of mercury to the atmosphere. Atmospheric Environment 30, 29812987.

Schroeder, W.-H., J. Munthe, 1998, Atmospheric Mercury - an Overview, Atmospheric Environment, 32, 809-822.

Seinfeld, J. H. and S.N. Pandis, 1998. Atmospheric Chemistry and Physics: From Air Pollution to Climate Change, John Wiley \& Sons, New York, ISBB: 